\title{
A SOCIOLOGIA COMPREENSIVA DE MICHEL MAFFESOLI: IMPLICAÇÕES PARA A PESQUISA EM ENFERMAGEM*
}

\author{
Juliana Fernandes da Nóbrega1, Rosane Gonçalves Nitschke², Ana Izabel Jatobá de Souza³,
} Evanguelia Kotzias Atherino dos Santos ${ }^{4}$

RESUMO: Trata-se de um estudo reflexivo sobre a Sociologia Compreensiva de Maffesoli e sua relação com trabalhos na área da saúde. O texto traz uma breve biografia do autor, suas noções e os cinco pressupostos teóricos e da sensibilidade. Maffesoli defende que o racionalismo estático, símbolo do pensamento moderno, precisa dar lugar à racionalidade aberta pós-moderna - a razão sensível - que apela para o entusiasmo, para o instinto. Para ele, é necessário que haja um equilíbrio entre razão e sentimento para analisar um fenômeno. Acreditando que há algo mais, além de números, medidas e desfechos, estudiosos têm proposto o uso da razão sensível no processo de pesquisa. Portanto, a Sociologia Compreensiva, ao oferecer outra visão sobre as relações humanas, contribui sobremaneira às pesquisas no meio acadêmico, em especial às pesquisas em Enfermagem. PALAVRAS-CHAVE: Pesquisa em enfermagem; Filosofia; Sociologia.

\section{THE INTERPRETIVE SOCIOLOGY OF MICHEL MAFFESOLI: IMPLICATIONS FOR NURSING RESEARCH}

\begin{abstract}
This is a reflexive study on Maffesoli's Interpretive Sociology and its relation with works in the healthcare area. The text includes a brief biography of the author, the author's notions, the five theoretical assumptions and sensitivity. Maffesoli defends that "static rationalism", a symbol of modern thought, needs to give way to the post-modern "open rationality" - sensitive reason - which appeals to enthusiasm, to instinct. To Maffesoli, to analyze a phenomenon, it is necessary that there should be a balance between reason and feeling. Believing that there is "something more", beyond "numbers, measures and outcomes", scholars have proposed the use of sensitive reason in the research process. However, Interpretive Sociology, by favoring another vision of human relations, contributes heavily to research in academic circles, especially in Nursing research.

KEYWORDS: Nursing research; Philosophy; Sociology.

\section{LA SOCIOLOGÍA COMPRENSIVA DE MICHEL MAFFESOLI: IMPLICACIONES PARA LA INVESTIGACIÓN EN ENFERMERÍA}

RESUMEN: Este es un estudio reflexivo sobre la Sociología Comprensiva de Maffesoli y su relación con trabajos en el área de la salud. El texto trae una breve biografía del autor, sus nociones y los cinco presupuestos teóricos y de la sensibilidad. Maffesoli defiende que el "racionalismo estático", símbolo del pensamiento moderno, debe ceder a la "racionalidad abierta" posmoderna - la razón sensible - que apela para el entusiasmo, para el instinto. Para él, es necesario haber equilibrio entre razón y sentimiento para analizar un fenómeno. Creyendo que hay algo más allá de "números, medidas y desenlaces", estudiosos han propuesto el uso de la razón sensible en el proceso de investigación. Por tanto, la Sociología Comprensiva, al ofrecer otra visión acerca de las relaciones humanas, contribuye mucho a las investigaciones en el medio académico, en especial a las investigaciones en enfermería. PALABRAS CLAVE: Investigación en enfermería; Filosofía; Sociología.

\footnotetext{
* Trabalho apresentado à disciplina de mestrado "Concepções teórico-filosóficas no processo de cuidar em enfermagem e saúde" do Programa de Pós-Graduação em Enfermagem da Universidade Federal de Santa Catarina- Pen UFSC.

${ }^{1}$ Enfermeira. Especialista em Saúde Pública. Mestranda pelo Pen UFSC. Professora do Instituto Federal de Santa Catarina. Membro do Núcleo de Estudos e Pesquisa em Enfermagem, Quotidiano, Imaginário e Saúde de Santa Catarina - NUPEQUIS.

${ }^{2}$ Enfermeira. Doutora em Enfermagem. Professora do Departamento de Enfermagem e do PEn UFSC. Líder do NUPEQUIS.

${ }^{3}$ Enfermeira. Doutora em Enfermagem. Professora do Departamento de Enfermagem e do PEn UFSC.

${ }^{4}$ Enfermeira. Doutora em Enfermagem. Professora do Departamento de Enfermagem e do PEn UFSC. Líder do Grupo de Pesquisa em Enfermagem na Saúde da Mulher e do Recém-Nascido - GRUPESMUR.
} 


\section{INTRODUÇÃO}

Michel Maffesoli, teórico da Sociologia Pós-Moderna, é fonte de inspiração para diversas pesquisas em Enfermagem. Suas ideias e pressupostos servem como base para estudos sobre o quotidiano e imaginário focalizando o processo saúde-doença. Fugindo do aspecto tecnicista da ciência atual, Maffesoli privilegia, enquanto objeto de análise, tudo aquilo que não é produzido pelo cálculo, pela intenção, pela estratégia, enfim, pela racionalidade tradicional; adotando a sociologia do aqui e agora. É com base neste fato que muitas pesquisas em Enfermagem têm optado por utilizar os 5 Pressupostos Teóricos e da Sensibilidade de Maffesoli, integrando a Sociologia Compreensiva com a Área da Saúde.

No presente texto apresentamos uma breve biografia do autor, um resumo das suas noções e dos pressupostos da Sociologia Compreensiva. Este manuscrito foi elaborado na disciplina de mestrado "Concepções teórico-filosóficas no processo de cuidar em enfermagem e saúde", utilizou como método uma busca nas principais obras do sociólogo e em trabalhos pertinentes com os objetivos da proposta.

\section{BREVE BIOGRAFIA DO AUTOR}

Michel Maffesoli, sociólogo francês, discípulo de Gilbert Durand e Julien Freund, nascido em Graissessac em 14 de novembro de 1944, casado, pai de quatro filhos, é professor de Sociologia da Universidade de Paris-Sorbonne Descartes ${ }^{(1)}$. Juntamente com Georges Balandier fundou, em 1982, o Centre d'Études sur l'Actuel et le Quotidien (CEAQ - Centro de Estudos sobre o Atual e o Quotidiano) ${ }^{(2)}$.

Publicou várias obras sobre o imaginário, quotidiano e viver, possibilitando visualizar o mundo com lentes provocativas e compreensivas. Dentre elas destacam-se: A Lógica da Dominação (1976); A Violência Totalitária (1979); A Sombra de Dionísio (1982); O Conhecimento Comum - Introdução à Sociologia Compreensiva (1985); O Tempo das Tribos (1988); A Transfiguração do Político (1992); Elogio da Razão Sensível (1996); Sobre o Nomadismo: Vagabundagens Pós-Modernas (1997); A Parte do Diabo - Resumo da Subversão Pós-Moderna (2002); O Ritmo da Vida Variações sobre o Imaginário Pós-Moderno (2004) (3). A recepção das obras de Maffesoli foi maior fora da França, em especial nos Estados Unidos, América Latina (incluindo o Brasil) e Extremo Oriente.

\section{ALGUMAS NOÇÕES DESENVOLVIDAS POR MAFFESOLI}

Maffesoli aborda o imaginário, a pós-modernidade, a investigação da vida quotidiana e a análise crítica do individualismo no que diz respeito ao ressurgimento das tribos.

Imaginário - Michel Maffesoli propõe uma sociologia da vida quotidiana centrada em teorias do imaginário. Buscando ideias de seu mestre, Gilbert Durand, acredita que a cultura não pode ser compreendida de forma integral, caso não se aceite que exista "algo a mais", ou seja, uma superação da cultura. Isto é o que se tenta captar por meio do imaginário. Segundo o autor, "o imaginário é algo que ultrapassa o indivíduo, que impregna o coletivo ou, ao menos, parte do coletivo"(4:76). Para Maffesoli, o imaginário pós-moderno reflete o tribalismo, isto é, o imaginário individual corresponde ao imaginário do grupo no qual o indivíduo se encontra inserido. O imaginário apresenta diversos elementos ou parâmetros: o racional, o onírico, o lúdico, a fantasia, o imaginativo, o afetivo, o não-racional, o irracional ${ }^{(4)}$.

Pós-modernidade - Vivemos em um mundo pósmoderno, onde não há mais adesão aos princípios de fachada que deixaram de ter qualquer vinculação com a realidade da vida. Para Maffesoli, "está chegando ao fim um ciclo, o que foi inaugurado com a consagração do bem como valor absoluto"(5:13), em que se deixa de lado o dever-ser, dando espaço a um viver dionisíaco, ou seja, "um hedonismo generalizado, selvageria latente, animalidade serena"(5:15).

Quotidiano - A maneira de viver de cada pessoa e do coletivo, o saber-fazer, saber-dizer e saber-viver define o quotidiano. O reaprendizado, presente neste, permite a evolução no processo de viver. "Existe, efetivamente, um 'conhecimento' empírico quotidiano que não pode ser dispensado"(6:195) e este torna relativa as certezas estabelecidas pelo racionalismo monovalente. Segundo Maffesoli, "de tanto nos interrogarmos sobre a sociedade ou sobre os elementos puramente racionais, intencionais ou econômicos que a constituem, terminamos por deixar de lado a socialidade, que é uma espécie de empatia comunalizada"(6:196).

Individualismo vs tribalismo: $\mathrm{O}$ pensamento pósmoderno considera que o ser humano não pode mais ser analisado individualmente. O imaginário de cada 
pessoa é resultante de um corpo social e que, de retorno, volta a materializar-se nele. Para Maffesoli, "toda a vida mental nasce de uma relação e de seu jogo de ações e retroações"(7:104). Há uma mudança de paradigma, onde o social (em que o indivíduo tem uma função na sociedade) dá lugar à socialidade (em que a pessoa representa papéis no theatrum mundi, tanto profissionalmente, quanto no seio das tribos de que participa). Nestas tribos, a aparência (estética) é importante como vetor de agregação, como cimento social, enquanto que a teatralidade instaura e reafirma a comunidade. Cada indivíduo é, ao mesmo tempo, ator e espectador ${ }^{(7)}$.

\section{PRESSUPOSTOS DA SOCIOLOGIA COMPRE- ENSIVA}

Maffesoli em seu livro "O conhecimento comum: compêndio de sociologia compreensiva" destaca 5 pressupostos teóricos e da sensibilidade. Estes já contemplaram trabalhos na área da saúde, em especial pesquisas em enfermagem que buscam entender os fenômenos levando em conta o quotidiano e o imaginário na pós-modernidade. Autores como Nitschke ${ }^{(8)}$, Ghiorzi $^{(9)}$, Fernandes ${ }^{(10)}$, Araruna ${ }^{(1)}$ e Souza ${ }^{(12)}$ respaldaram seus estudos nas obras de Maffesoli, utilizando na metodologia os 5 pressupostos teóricos e da sensibilidade que serão descritos a seguir.

Crítica do dualismo - Para Maffesoli, é de extrema importância que haja uma dosagem sutil entre erudição (crítica, razão) e paixão (sentimento, imaginação) para que se possa avaliar da melhor maneira possível um fenômeno qualquer. Nos tempos pós-modernos, há uma saturação dos grandes sistemas explicativos, com o renascimento da exploração da biografia.

O pensador, 'aquele que diz o mundo', não se deve abstrair; é que ele faz parte daquilo que descreve e, situado no plano interno, é capaz de manifestar uma certa visão de dentro, uma 'in-tuição' $6: 25)$.

Ou seja, tudo o que diz respeito à vida quotidiana - as experiências vividas, as crenças, a interação com outras pessoas e com o ambiente - deve ser levado em conta, tanto do ponto de vista sociológico, como em outras áreas do conhecimento. Maffesoli advoga que o racionalismo estático, símbolo do pensamento moderno, deve dar lugar à racionalidade aberta da pós-modernidade, que apela para o entusiasmo, para o instinto. É o que chama de razão sensível. Segundo o mesmo, "o afeto, o emocional, o afetual, coisas que são da ordem da paixão, não estão mais separados em um domínio à parte"(13:53) e servem como ferramentas metodológicas para a reflexão epistemológica. A simples razão, base durante toda a modernidade, não é o bastante. É preciso haver integração entre razão e componentes da personalidade, resultando em um alargamento da consciência ${ }^{(13)}$.

Crítica à Forma - Neste pressuposto o autor traz sua noção de formismo, criticando a forma que limita e fecha o significado. O formismo permite descrever os contornos por dentro, ou seja, do interior, esta atitude respeita o efêmero e as insignificâncias da vida quotidiana. Ou seja, "a forma permite a apreensão da imagem e de sua pregnância no corpo social" ${ }^{\prime(6: 29)}$. O essencial é o cíclico processo de construção/destruição. Assim, Maffesoli sugere remexer aqueles conceitos que pareciam estruturados e acabados e nos traz que o que verdadeiramente importa são as inquietações e questionamentos do que as respostas ${ }^{(14)}$.

Sensibilidade Relativista - Não existe uma realidade única, nosso viver é heterogêneo e plural exigindo compreensão ampla e integral. Este pressuposto declara que a verdade é sempre factual e momentânea. Da mesma forma, não há novidades nas histórias humanas, cujos valores retornam de modo cíclico. O que muda é a reflexão tecnicista ${ }^{(6)}$.

Pesquisa Estilística - Aqui a proposta é proceder como se, ao invés do por quê. Ressaltando a diversidade e fazendo um alerta para que a ciência leve em consideração o nosso tempo expondo-se através de um feed-back constante entre empatia e forma. Sugerindo também uma escrita mais aberta sem perder a competência científica ${ }^{(6)}$.

Pensamento Libertário - O pesquisador é também ator e participante, sendo importante a compreensão e exercício da ação de colocar-se no lugar do outro, apontando que é preciso uma atitude de empatia, subjetividade e intersubjetividade. Segundo o sociólogo, deve-se "trabalhar pela liberdade do olhar. É ela a um só tempo insolente, ingênua, mesmo trivial e, menos incômoda - mas abre brechas e permite intensas trocas" ${ }^{\natural(6: 41)}$.

\section{CONSIDERAÇÕES FINAIS}

Seguindo os pressupostos de Maffesoli, a Enfermagem tenta compreender o ser humano em sua 
totalidade. Como já enfatizado, é necessário que haja um equilíbrio entre razão e sentimento, no que se refere à análise de um fenômeno. Acreditando que há "algo mais", além de "números, medidas e desfechos", estudiosos têm proposto o uso da razão sensível para subsidiar o processo de pesquisa. A ciência moderna "tradicional" limita os estudos ao homogeneizar os indivíduos em pesquisa e tende a avaliar desfechos objetivos. Isso restringe a análise, pois os seres humanos são influenciados por fatores outros que não os racionais. O estudo do quotidiano preenche este vazio da modernidade, onde o que vale é o que pode ser mensurado. A Sociologia Compreensiva de Maffesoli cria outro paradigma nas pesquisas científicas, valorizando não somente os aspectos da razão - que também são essenciais - mas também os aspectos impalpáveis, como os do sentimento e do imaginário.

A Sociologia Compreensiva procura entender "o imprevisível, dando valor ao casual, ao banal, às inconcretudes, às apresentações incompletas da vida e as ações subjetivas dos sujeitos nos seus ambientes de relações"(15:317).

Conclui-se, então, que a Sociologia Compreensiva, ao oferecer outra visão sobre as relações humanas, contribui sobremaneira às investigações acadêmicas, em especial nas pesquisas em Enfermagem onde se torna essencial compreender como cada pessoa vivencia o processo saúde-doença ${ }^{(16)}$.

\section{REFERÊNCIAS}

1. Centre d'Études sur l'Actuel et Quotidien [Internet]. Curriculum vitae du Prof. Maffesoli [acesso em 02 jul 2011]. Disponível: http://www.ceaq-sorbonne.org/node. php?id $=91$.

2. Centre d'Études sur l'Actuel et Quotidien [Internet]. Histoire du CEAQ [acesso em 02 jul 2011]. Disponível: http://www.ceaq-sorbonne.org/node.php?id=55.

3. Michel Maffesoli [Internet]. Livres [acesso em 02 jul 2011]. Disponível: http://www.michelmaffesoli.org/ livres.

4. Silva JM. O imaginário é uma realidade. Rev. FAMECOS. 2001;15:74-82.

5. Maffesoli M. A parte do diabo - resumo da subversão pós-moderna. Rio de Janeiro: Record; 2004.

6. Maffesoli M. O conhecimento comum. Compêndio de Sociologia Compreensiva. São Paulo: Brasiliense; 1988.
7. Maffesoli M. O tempo das tribos. O declínio do individualismo nas sociedades de massa. $2^{\text {a }}$ ed. Rio de Janeiro: Forense Universitária; 1998.

8. Nitschke RG. Mundo imaginal de ser família saudável no cotidiano em tempos pós-modernos: a descoberta dos laços de afeto como caminho [tese]. Florianópolis (SC): Universidade Federal de Santa Catarina; 1999.

9. Ghiorzi AR. Entre o dito e o não dito: da percepção à expressão comunicacional. Florianópolis: Universidade Federal de Santa Catarina; 2004.

10. Fernandes SLSA. O quotidiano com seus limites e forças para o ser saudável: um encontro da enfermagem com a potência para contornar a violência no dia-a-dia [tese]. Florianópolis (SC): Universidade Federal de Santa Catarina; 2007.

11. Araruna RC. Mundo imaginal e a potência de ser família saudável frente a violência no quotidiano [tese]. Florianópolis (SC): Universidade Federal de Santa Catarina; 2007.

12. Souza LCSL. O quotidiano de cuidado de enfermagem: um encontro entre as imagens dos profissionais e das famílias [tese]. Florianópolis (SC): Universidade Federal de Santa Catarina; 2008.

13. Maffesoli M. Elogio da razão sensível. Petrópolis: Vozes; 1998.

14. Maffesoli M. O ritmo da vida. Variações sobre o imaginário pós-moderno. Rio de Janeiro: Record; 2007.

15. Pereira A. O Quotidiano como referência para a investigação das intervenções de enfermagem. Rev. Gaúcha enferm. 2005;26(3):316-25.

16. Camargo C, Quirino M, Morais A. A etnografia nas pesquisas de enfermagem com ênfase no cuidado. Cogitare enferm. [Internet] 2011;16(3) [acesso em 25 dez 2011]. Disponível: http://ojs.c3sl.ufpr.br/ojs2/index. php/cogitare/article/view/17807/16299. 